\title{
Meta-heuristic Global Optimization Algorithms for Aircraft Engines Modelling and Controller Design; A Review, Research Challenges, and Exploring the Future
}

by

S. Jafari, T. Nikolaidis.

Centre for Propulsion Engineering

School of Aerospace Transport and Manufacturing (SATM)

Cranfield University, Cranfield, Bedfordshire, MK43 0AL, UK.

* Corresponding author: E-mail: S.jafari@cranfield.ac.uk 


\begin{abstract}
Utilizing meta-heuristic global optimization algorithms in gas turbine aero-engines modelling and control problems is proposed over the past two decades as a methodological approach. The purpose of the review is to establish evident shortcomings of these approaches and to identify the remaining research challenges. These challenges need to be addressed to enable the novel, cost-effective techniques to be adopted by aero-engine designers. First, the benefits of global optimization algorithms are stated in terms of philosophy and the nature of different types of these methods. Then, a historical coverage is given for the applications of different optimization techniques applied in different aspects of gas turbine modelling, controller design, and tuning fields. The main challenges for the application of meta-heuristic global optimization algorithms in new advanced engine designs are presented. To deal with these challenges, two efficient optimization algorithms, Competent Genetic Algorithm in single objective feature and aggregative gradient-based algorithm in multi-objective feature are proposed and applied in a turbojet engine controller gaintuning problem as a case study. A comparison with the publicly available results show that optimization time and convergence indices will be enhanced noticeably. Based on this comparison and analysis, the potential solutions for the remaining research challenges for application to aerospace engineering problems in the future include the implementation of enhanced and modified optimization algorithms and hybrid optimization algorithms in order to achieve optimal results for the advanced engine modelling and controller design procedure with affordable computational effort.
\end{abstract}

Keywords: Meta-heuristic, Global Optimization algorithm, Gas Turbine Modelling and Control, New Engine Designs, Competent Genetic Algorithm, Aggregative gradientbased.

\title{
Nomenclature
}

BBs: Building Blocks

CDP: Compressor Discharge Pressure

CGA: Competent Genetic Algorithm

COM: Control Oriented Model

CPR: Compressor Pressure Ratio

CSD: Control Structure Design 
EA: Evolutionary Algorithms

EPR: Engine Pressure Ratio

GO: Global optimization

GTE: Gas Turbine Engine

HPS: High Pressure Shaft

IFPC: Integrated Flight/Propulsion Control

LPS: Low Pressure Shaft

LP: Linear Programming

MEA: More Electric Aircraft

MGO: Meta-heuristics Global Optimization

MILP: Mixed-integer Linear Programming Problems

MINLP: Mixed-integer Non-linear Programming Problems

$\dot{m}_{f}$ fuel flowrate to the combustion chamber

$\left\{\dot{m}_{f}\right\}_{\max }$ Maximum allowable fuel flowrate to the combustion chamber

NEA: New Efficient Aircraft

NGDF: Novel Generalized Describing Function

NLP: Non-linear Programming Problems

PLA: Pilot Lever Angle

$P_{i}$ Penalty functions

SO: Stochastic optimization

sim_time Simulation time;

sampleTime Time step;

$t$ Time index; 
$t_{a c c}, t_{d e c}$ Acceleration and deceleration times;

UAV: Unmanned Aerial Vehicle

$\alpha_{i}$ Weighting coefficients for penalty functions

$\beta_{i}$ Weighting coefficients for objective function

91 references Figures 1-14 Tables 1-5 No appendices 


\section{Introduction}

Global optimization (GO) algorithms are effective means to improve modelling and analysis procedure in a very diverse range of real-world engineering applications with respect to their flexibility and model independent nature. Over the past decades, the application of global optimization algorithms in aircraft engines modelling and control has been widely used in a systematic approach. However, with recent advances in aircraft and engines, we are currently facing much more complex problems with many more parameters to design and tune. The new aircraft engines are increasingly complex with respect to the high demanding designs of New Efficient Aircraft (NEA) and More Electric Aircraft (MEA) in terms of new configurations, structures, and electric components. So, the current global optimization algorithms should be revisited from efficiency and computational affordability points of view to deal with these new challenges.

This paper reviews and analyses the proposed global optimization algorithms application for aircraft engines modelling and control from a historical viewpoint and then discusses the research challenges to summarize the reasons of considering new/modified GO algorithms in design, tuning, and optimization problems. The paper also investigates the application of two newly established optimization algorithms, Competent Genetic Algorithm (CGA) and aggregative gradient-based method, applied in a turbojet engine controller gain-tuning as a case study and compares the results with those of other global optimization approaches to address the remaining research challenges associated with the field; which if solved, will hopefully remove the major obstacles for implementation of these methods in the future engines design as well. 
The underlying principle behind all GO algorithms is to focus on finding the maximum or minimum of a function over all input values, as opposed to finding local minima or maxima. This is in contrast to analytical optimization algorithms, which find the optimum of functions using pure analytical approaches to select the best element (with regard to some criteria) from some set of available alternatives. Application of global optimization techniques in gas turbine engine problems have been reported in [1] and [2], and more recently in [3]. Analytical methods are however reaching their limits for efficient modelling parameters set, controller structure design and controller gain tuning, especially for the new-established advanced high-quality controllers with numerous variables. These limitations give an impulse to the exploration for alternative cost-effective and efficient optimization methods. Recognizing the challenges, global optimization algorithms have the potential to overcome these limitations as they have certain benefits.

To categorise the main benefits, it is clear that in a Gas Turbine Engine (GTE) modelling and control system, there are huge number of parameters that should be designed and regulated simultaneously. This should be done in order to achieve an optimized performance for the engine. As an example, the fuel controller design for a single spool turbojet engine is a 14-Dimensions problem [3]. The dimension of the problem increases to 20 for a simple integrated flight/propulsion control (IFPC) for an Unmanned Aerial Vehicle (UAV) [4]. Obviously, many more parameters should be designed and tuned for more complex engine architectures, e.g. turbofans and turboshafts. Moreover, it is clear that the analytical optimization and gain tuning tools have all easily become stuck in the local optimums and their implementations are not affordable for huge problems especially from computational efforts point of view. However, the global optimization algorithms are the right choices for this kind of 
problems because of their technically proved relative merits. These algorithms can easily deal with both linear and nonlinear problems, their application is simple and straightforward, they are useful in problems in the presence of noise, and they are robust with respect to growth of dimension [5].

Over the past 20 years, i.e. from the earliest evidence of using non-analytic optimization algorithms in GTE modelling and performance optimization, three different fields have been considered:

- $\mathrm{GO}$ algorithms in GTE modelling problems

- GO algorithms in GTE controller structure design problems

- GO algorithms in GTE controller gain tuning problems

To cover all the above-mentioned fields in this paper, the mathematical principles and benefits of GO algorithms are firstly discussed in section two. A history of gas turbine aero-engine modelling and control using GO algorithms is then covered in section three in which all claims and conclusions are confirmed with references, simulations, or experimental data. Based on the presented history, the challenges of using metaheuristic GO algorithms for new advanced GTE designs are identified in section four. Moreover, the potential solutions for identified challenges are introduced and the effectiveness of the proposed solutions are confirmed by simulation results. After that, the future of GO in GTE design and performance optimization is discussed in detail.

\section{Mathematical principles and benefits of global optimization algorithms}

Global optimization is a branch of applied mathematics dealing with globally minimization/maximization of a set of functions regarding some criteria, bounds and constraints. In other words, global optimization is illustrious from customary 
optimization because it focuses on finding the optimum over all input values, as opposed to finding local minima or maxima.

Generally, the global optimization algorithms could be categorised into three main categories: deterministic global methods, stochastic methods, and metaheuristics.

Deterministic global optimization would guarantee that the developed solution is indeed the global one within some predefined tolerance [5]. The term deterministic global optimization typically refers to complete (the method reaches a global minimum with certainty, assuming exact computations and indefinitely long run time) or rigorous optimization (the method reaches a global minimum with certainty and within given tolerances even in the presence of rounding errors). Consequently, the problem with deterministic global optimization methods is that they cannot give a rigorous result when working with black-box or incomplete models (codes without any knowledge of its internal workings). Linear Programming (LP) [6], Mixed-integer linear programming problems (MILP) [7], Non-linear programming problems (NLP) [8], and Mixed-integer non-linear programming problems (MINLP) [9] are different classes of deterministic global optimization techniques.

Stochastic optimization (SO) methods are coping with random variables, random objective functions, and random constraints [10]. These algorithms are suitable for the problems in the areas of real-time estimation and control, simulation-based optimization where Monte Carlo simulations are run as estimates of an actual system, $[11,12]$ and problems where there is experimental (random) error in the measurements of the criterion. The SO classes are stochastic approximation (SA) [13], stochastic gradient descent, finite-difference SA [14], simultaneous perturbation SA [15], and scenario optimization. The problem with these algorithms is that even when the data set consists of precise measurements, some methods introduce randomness 
into the search-process to accelerate progress. Such randomness can also make the method less sensitive to modelling errors.

Metaheuristic optimization methods are high-level procedures to find a global solution for an optimization problem with incomplete/imperfect information using partial search algorithms (heuristics) [16]. Therefore, these approaches are usable for a wide variety of problems in real-world applications [17]. Although metaheuristic optimization methods do not guarantee finding a global optimal solution on some class of problems [18], they usually find a good solution with less computational effort than those of other global optimization methods by searching over a large set of feasible solutions $[17,18]$. Consequently, the metaheuristic optimization approaches are more useful in practical problems than other approaches [17-21].

Table 1 summarizes the main advantages and disadvantages of the global optimization algorithms. With respect to their efficiency and practicality, metaheuristics global optimization (MGO) algorithms are more effective in real-world engineering problems. Hence, the rest of the paper will focus on this type of optimization algorithms. A comprehensive review of the application of these methods in gas turbine aero-engine modelling and control problems is presented in the next section. 
Table 1 - Comparison between different categories of global optimization algorithms

\begin{tabular}{|c|c|c|c|}
\hline & GO Method & Advantages & Disadvantages \\
\hline 1 & $\begin{array}{l}\text { Deterministic } \\
\text { Optimization }\end{array}$ & $\begin{array}{l}\text { Guarantee finding the exact } \\
\text { solution (global optimal) with } \\
\text { a given tolerance }\end{array}$ & $\begin{array}{l}\text { - } \text { Not working with } \\
\text { incomplete/imperfect } \\
\text { models } \\
\text { - } \text { Assuming exact } \\
\text { computations and } \\
\text { indefinitely long run time }\end{array}$ \\
\hline 2 & $\begin{array}{l}\text { Stochastic } \\
\text { Optimization }\end{array}$ & $\begin{array}{l}\text { Capability of working with } \\
\text { random variables, objective } \\
\text { functions, and constraints }\end{array}$ & $\begin{array}{l}\text { - Introduce randomness to } \\
\text { search process to } \\
\text { accelerate progress } \\
\text { - Less sensitive to system } \\
\text { errors and noises }\end{array}$ \\
\hline 3 & $\begin{array}{l}\text { Metaheuristic } \\
\text { Optimization }\end{array}$ & $\begin{array}{l}\text { Deal with all types of } \\
\text { problems especially real- } \\
\text { world engineering problems } \\
\text { even with } \\
\text { incomplete/imperfect } \\
\text { information }\end{array}$ & $\begin{array}{l}\text { Do not guarantee finding global } \\
\text { optimal solutions in some class } \\
\text { of problems }\end{array}$ \\
\hline
\end{tabular}

\section{A history of gas turbine aero-engine modelling and control using meta-} heuristic global optimization algorithms

A GTE is the heart of any airplane that provides the propulsive force, thrust, (by pulling air through an inlet, compressing it, combusting it with fuel, and allowing the exhaust to expand through a turbine) for flight in response to the pilot command. What the pilot 
usually wants to achieve while moving the thrust lever is to let the engine deliver a certain percentage of the thrust that is available at the current flight condition [22]. Since thrust itself is not measurable in flight, the relative thrust command given by the Pilot Lever Angle (PLA) setting must be translated into a command change of a measured variable. Therefore, the engine controller should be able to translate the pilot command to other measurable parameters using their sensors and actuators (or based on a control-oriented model (COM)). In order to design and regulate such a controller, a simple, fast, and precise COM is required at the first step. Both modelling and control procedures involve several parameters, gains, and structures that should be designed and regulated simultaneously. Taking into account the nonlinearity and switching nature of modelling and controller design approaches, the global optimization algorithms can be used in the following stages:

- $\quad$ GTE model parameters tuning

- $\quad$ GTE control structure design (CSD)

- $\quad$ GTE controller gain tuning

A historical review of application of MGO algorithms in the above-mentioned fields is presented in this section.

\subsection{Metaheuristic global optimization algorithms in control oriented model design of gas turbine engines}

The emergence of simple models for control reason was in 1952 when Gold and Rosenzweig estimated the relationship between the engine fuel flow and rotational speed as a first order transfer function [23]. Then, Powell and Lowrence modified the previous work in 1957 based on the fact that the response of the turbine torque is faster than that of the compressor in the case of the sudden increase in the engine 
fuel flow [24]. They also showed that the defined time constant in the transfer functions is a function of GTE rotational speed $[25,26]$. Next step was the research studies of Fitchie in the UK National Gas Turbine Establishment on the Olympus101 engine. He showed that the dynamic behaviour of a two-spool GTE can be estimated with two separate transfer functions, each of them having one zero and two poles [27] where the poles were the same for both Low Pressure Shaft (LPS) and High Pressure Shaft (HPS). He also estimated the time constants as a function of partial differential of shaft torques, fuel flow rate and rotational speed and showed that a pole-zero cancellation occurred in the LPS transfer function. His conclusion was confirmed later by Staff as well $[28,29]$. In general, subsequent studies were accomplished based on the Fitchie conclusion [30].

In 2003, Kullikov reviewed the application of block-structure models for the gas turbine engine modelling procedure [31]. These models consist of a linear dynamic part to simulate all engine lags and a nonlinear static part to simulate the relationship between the different engine parameters. The model parameters are usually tuned by the experimental results. There are four architectures for block-structure models, including Hammerstein, Wiener, Wiener-Hammerstein, and Hammerstein- Wiener models [32]:

- A Hammerstein model is an approximate expression for systems where nonlinearity only resulted from the change of direct-current gain with input amplitude; so, this model cannot depict the aircraft engine operating process because the engine dynamics distinctly varied with the input amplitude.

- The Wiener model on the other hand shows variations of dynamic behaviour for different input amplitudes. The Wiener model has a simpler structure than the Wiener-Hammerstein model, and it requires fewer model parameters to be computed. Hence, the Wiener model is used to depict engine dynamic 
behaviour varying with operating conditions and is recommended for engine identification.

- Wiener-Hammerstein and Hammerstein- Wiener models have a relatively large number of variables and the required data to determine the model parameters of the superimposed model are hard to produce [33].

Consequently, the Wiener model is the best choice for GTE block-structure modelling. The schematic of these models is presented in figure 1.

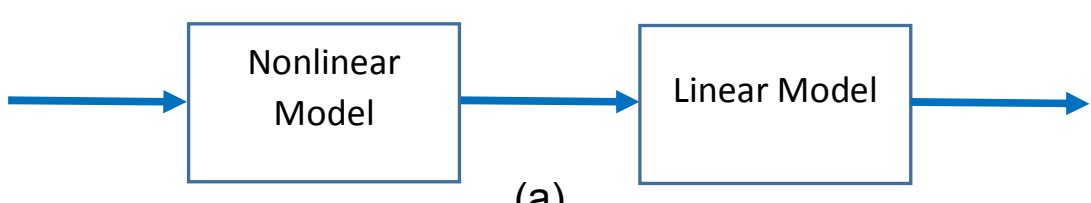

(a)

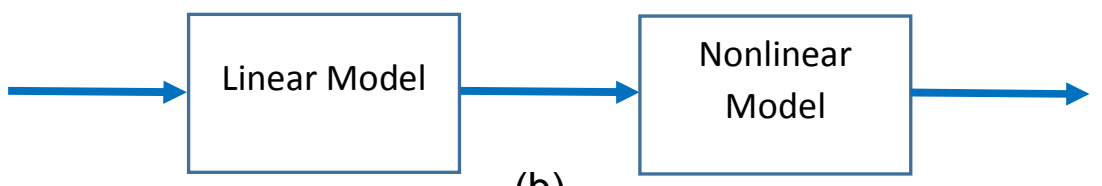

(b)

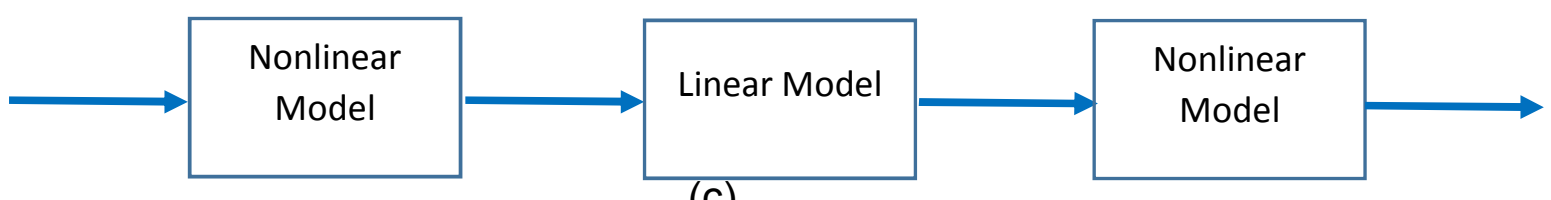

(c)

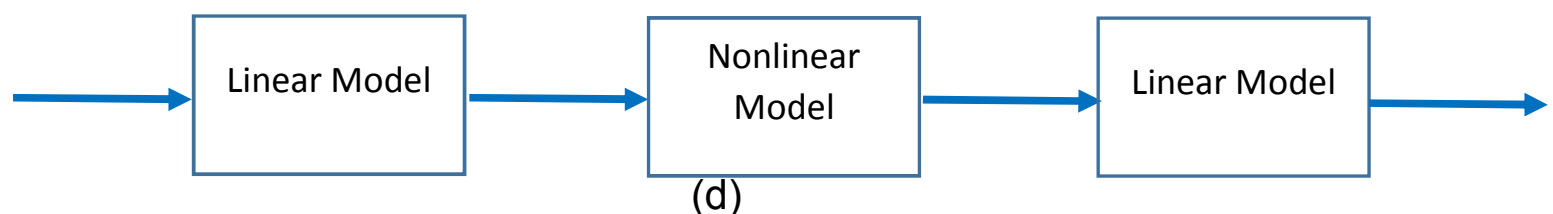

Figure 1. Block structure model schematics (a) Hammerstein (b) Wiener (c)

Hammerstein- Wiener (d) Wiener-Hammerstein

Lichtsinder and Levy proposed another precise method called Novel Generalized Describing Function (NGDF) for gas turbine COM development [34]. As shown in figure 2, the NGDF is based on the error minimization concept and the difference 
between the NGDF model and the models proposed by other researchers is that in NGDF the transfer functions between different inputs and outputs has an incremental form to enhance the accuracy of the model.

In order to show that this method has the highest accuracy between the different blockstructures modelling approaches, a single spool turbojet engine is modelled in this paper using different modelling approaches, transfer function described in [29], Wiener block structure described in [31], and NGDF described in [34]. The engine specification is shown in figure 3 . The results are compared with experimental data obtained from a ground test to confirm the effectiveness of the NGDF method in GTE modelling for control purpose.

As shown in figure 4 , the NGDF tracks the engine parameters with a very high accuracy in both steady state and transient operations. More details about the engine modelling procedure and used equations could be found in [31-35]. In addition, Andoga et al. did a comprehensive literature survey on the reduced order model generation procedure for the gas turbine aero-engines in 2008 and with several simulations showed that the effect of the second order term of the LPS is not negligible in high bypass turbofan engines [36].

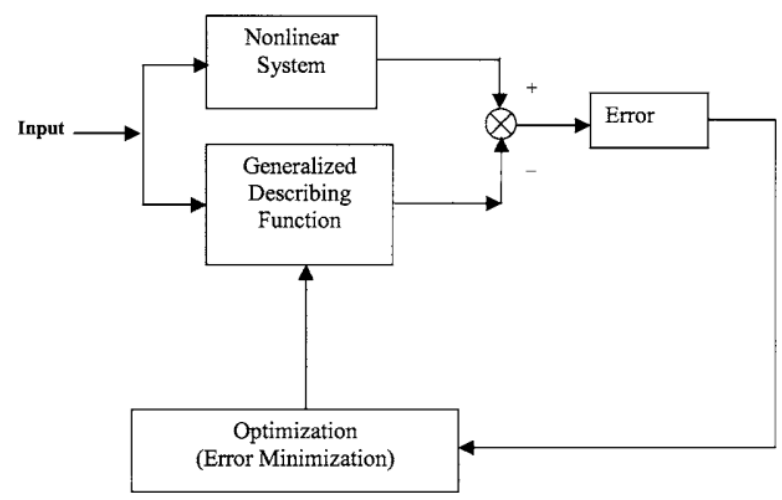

Figure 2. The schematic of NGDF for modelling jet engines [34] 


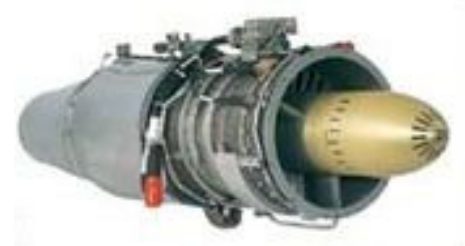

General characteristics

- Type: Single Spool Turbojet

- Length: $851 \mathrm{~mm}$

- Diameter: $348 \mathrm{~mm}$

- Dry weight: $61.2 \mathrm{~kg}$

Components

- Compressor: 4 stage axial

- Combustors: Annular

- Turbine: Single Stage

Performance

- Maximum thrust: $5.33 \mathrm{kN}$

- Overall pressure ratio: 6.3:1

- Air mass flow: $8.14 \mathrm{~kg} / \mathrm{s}$

- Specific fuel consumption: $1.1 \mathrm{~kg} /(\mathrm{daN} h)$

- Thrust-to-weight ratio: 8.9:1

Figure 3. The schematic and characteristics of the modelled turbojet engine (images from [37])

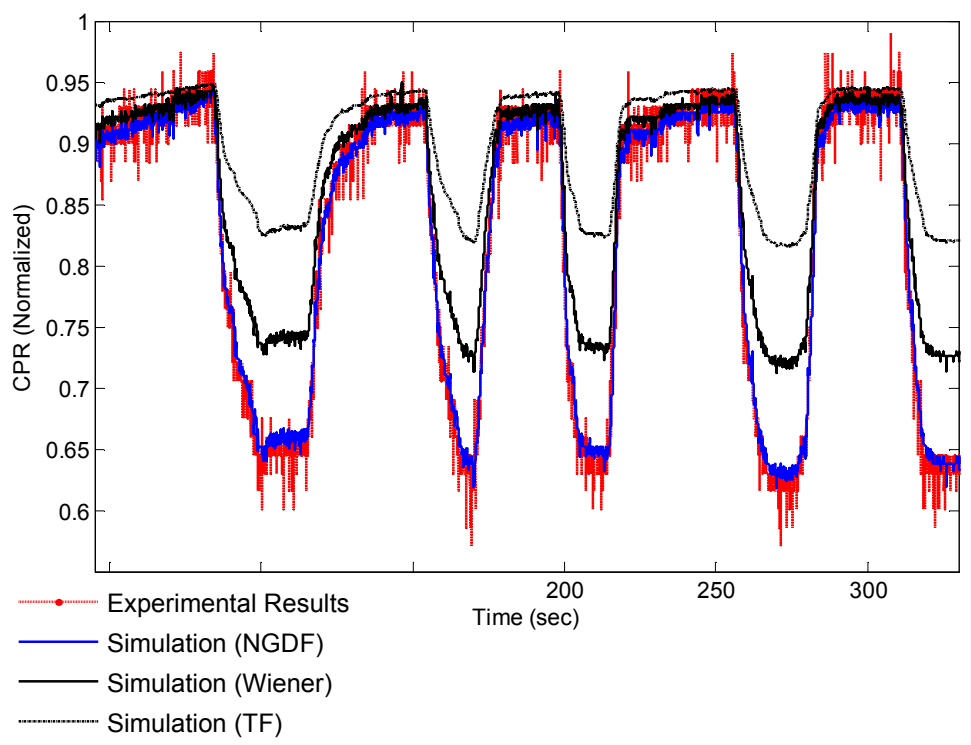

(a) 


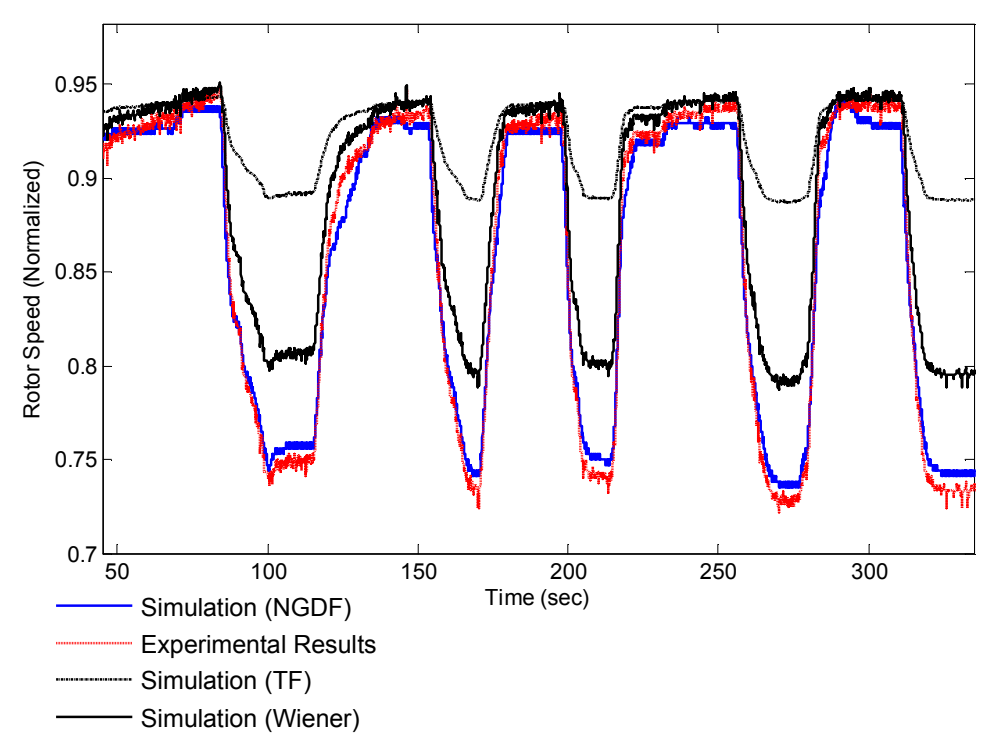

(b)

Figure 4. Modelling a turbojet engine with different reduced order approaches (a) Normalized Compressor Pressure Ratio (CPR) tracking (b) Normalized Rotor speed tracking

All the above-mentioned approaches suffer from the complexity of the parameters tuning procedure. Trial and error methods, geometrical methods, empirical methods, and other analytical approaches, were used in this regard. However, none of them were able to deliver acceptable results from the level of accuracy and running time point of view.

It was in 1997 that Rodriguez et al. used MGO algorithms for simplification of the parameters identification procedure in gas turbine aero-engines [38]. They proposed a Genetic Programming-NARMAX approach firstly to identify a non-linear model for a GTE. Then, they extended their method to a multi-objective form with the aim of simultaneously optimizing different measures of the system model [39]. Later on, Fleming modified the basic Genetic Algorithm (GA) and presented the studGA (in which a crossover pool was added to genetic algorithm to enhance its convergence speed) [40-41]. He applied his proposed method in the optimization of a GTE 
performance and showed that his method could practically enhance the efficiency of the genetic algorithm. Ashlock presented a comprehensive study on evolutionary computation for modelling and optimization in 2004 [42]. In simple words, he defined the application of the Evolutionary Algorithms (EA) for modelling real-world systems as the pseudo code of figure 5 .

Generate a population of structures

Repeat

Test the structures for quality

Select structures to reproduce

Produce new variations of selected structures

Replace old structures with new ones

Until Satisfied

\section{End}

Figure 5. The fundamental structure of an evolutionary algorithms [42]

In 2007, Cranfield University introduced a Techno-economic and Environmental Risk Assessment (TERA) model as a multi-disciplinary module for modelling gas turbine and aircraft performance, which is integrated with a commercial optimizer and provides a means for cycle studies. The results of the report confirmed that the TERA potential for aircraft and engine performance modelling and management is bright [43].

In 2012, Tsoutsanis et al. used genetic algorithm for an off-design performance adaptation approach in the gas turbine performance simulation. They applied their method to a GE LM2500+ aero-derivative gas turbine operating in Manx Electricity Authority's combined cycle power plant on the Isle of Man to confirm its advantages in 
comparison with other adaptation approaches. This is achieved by employing a compressor map generation method, which introduces coefficients to control the shape of the maps. The coefficients from the map generation procedure are optimized by GA in order to match as accurately as possible the targeted measurements of an engine working at part load conditions [44]. The flowchart of the approach taken by Tsoutsanis et al. is presented in figure 6.

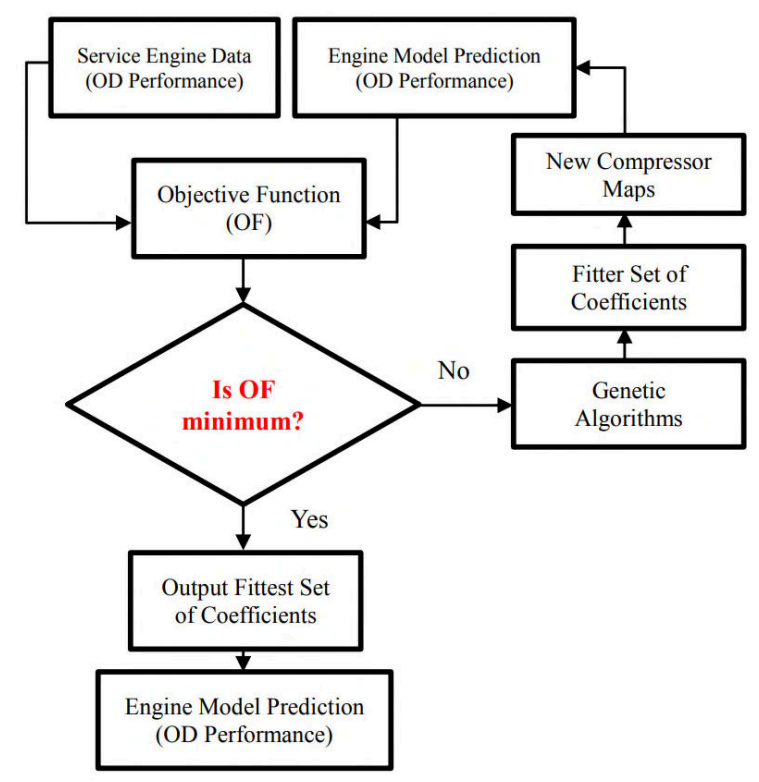

Figure 6. Flowchart of gas turbine performance adaptation method used in [44]

Celis et al. reported the last progress of the TERA in Cranfield University in 2015. In their study, the TERA was utilised in conjunction with an in-house optimiser to carry out aircraft engine cycle optimisation processes to confirm the future potential for optimising the preliminary design of GTEs and determining optimum as well as greener aircraft engine cycles [45].

In general, the flowchart of utilizing global optimization algorithms for gas turbine engine modelling reasons could be summarized as follows: 
I. Select the model structure based on the required level of accuracy, simplicity, and run time (Block-structure model, Transfer function model, NGDF model, Thermodynamic model, etc.)

II. Define the objective function to be minimized/maximized as a function of model parameters (e.g. error (model parameters) $=\mid$ Simulation results(engine model parameters)-Experimental/ verified results | )

III. Use the appropriate MGO algorithm to find the optimized/ set of optimized parameters

IV. Set the optimization algorithm parameters and run the optimization procedure (e.g. figure 5)

V. Run a decision making procedure to select the best parameters for the model

\subsection{Metaheuristic global optimization algorithms in control structure design of gas turbine engines}

As mentioned earlier, since thrust is not measurable directly, the controller should be able to translate this parameter into other measureable ones based on the position of the PLA set by the pilot at any instantaneous time. Different parameters are used in the literature and industrial reports for this purpose. General Electric (GE) used the first industrial control algorithm for the gas turbine engine by the engine rotational speed sensor and a gain scheduling strategy as shown in figure 7 [46]. Since there is a nonlinear relationship between the rotational speed and the engine thrust, the performance curves of the engine are used for tuning of the controller and for converting the pilot demanded thrust to the engine rotational speed in different operating conditions. In the strategy proposed by GE, the compressor discharge 
pressure (CDP) was used as limiting factor to satisfy the physical limitation control modes [47].

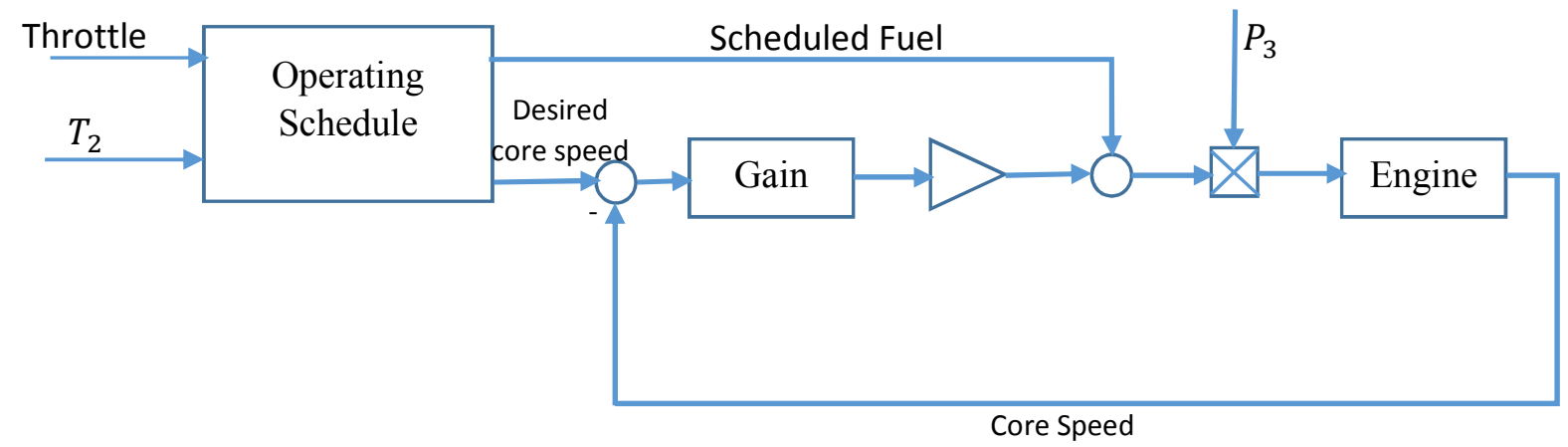

Figure 7. Schematic of gas turbine control algorithm used by GE based on engine rotational speed [46]

The other control strategy used by Rolls Royce and also Pratt and Whitney (P \& W) was using the Engine Pressure Ratio (EPR) to calculate the appropriate fuel flow for the engine at different PLA positions [46]. The structure of the algorithm is shown in figure 8. The engine rotational speed was used as limiting factor to satisfy the physical limitation control modes in this approach. The relationship between the EPR and the thrust is less nonlinear than those of rotational speed. But on the other hand, the pressure sensor responses are usually noisy. The pros and cons of these algorithms as well as a comprehensive history of different control strategies for gas turbine aeroengines are discussed in [48-50].

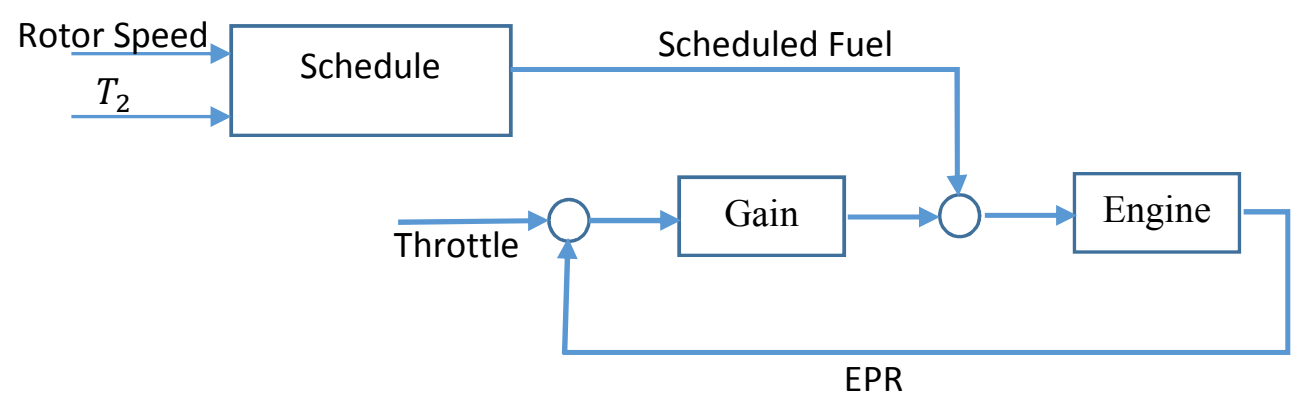


Figure 8. Schematic of gas turbine control algorithm based on engine pressure ratio [46]

The above-mentioned industrial algorithms were easy to implement and straightforward. However, their main issue was to deal with physical limitation control modes. In other words, using such simple control algorithms could not guarantee the satisfaction of all engine control models (steady state control mode, transient control mode, and physical limitations control mode) simultaneously. Consequently, the idea of Min-Max control algorithms was proposed and widely used by the industry. The main idea of Min-Max controller is to have separate control loops; a steady-state control loop, a transient-control loop, and some physical limitation control loops (e.g. to limit the maximum acceleration, deceleration, turbine inlet temperature, engine shafts rotational speeds, etc.). At any instantaneous time, a pre-defined Min-Max control strategy selects the appropriate active control loop (the winner loop) for the engine. This guarantees satisfying all engine control modes simultaneously. This method is widely used by well-known manufacturers (e.g. Rolls-Royce, MTU Aero Engines, Volvo Aero Corporation, Fiat Avio,Techspace Aero S.A, Lufthansa Technik AG, Aerospatiale, Chalmers University of Technology AB, National Technical University of Athens, Technische Universität München, Universität Stuttgart, Université Catholique de Louvain $[49,51])$. The schematic of a simple Min-Max control structure for a turbojet engine is shown in figure 9. It contains a steady state control loop which normally is a gain-scheduling controller to provide the minimum required fuel flow to keep the engine in the current steady state condition. There is also a transient control loop which is the winner of the Min-Max strategy between the pilot command and the physical limitations of the engine to satisfy all engine control modes 
simultaneously. For instance, for the Min-Max controller of figure 9, this strategy could be defined as follow:

$$
\begin{aligned}
& \mathrm{W}_{\mathrm{f}-\text { Transient }}=\text { Min }\left(\operatorname{Min}\left(\operatorname{Max}\left(\mathrm{W}_{\mathrm{f}-\mathrm{dec}}, \mathrm{W}_{\mathrm{f}-\mathrm{PLA}}\right), \mathrm{W}_{\mathrm{f}-\mathrm{acc}}\right), \mathrm{W}_{\mathrm{f}-\mathrm{Nmax}}\right) \\
& \mathrm{W}_{\mathrm{f}-\text { Total }}=\mathrm{W}_{\mathrm{f}-\text { Steady }}+\mathrm{W}_{\mathrm{f}-\text { Transient }}
\end{aligned}
$$

Where $\mathrm{W}$ is the value of the fuel flow of different loops shown in the figure 9.

More control loops could be added to the min-max control structure and strategy for different purpose like control of the second spool and fan speed in turbofan engines etc. The main advantage of the Min-Max control algorithms is that they are able to consider all engine control modes simultaneously. However, by increasing the number of control loops, the design and tuning procedure will be more and more complex and time consuming.

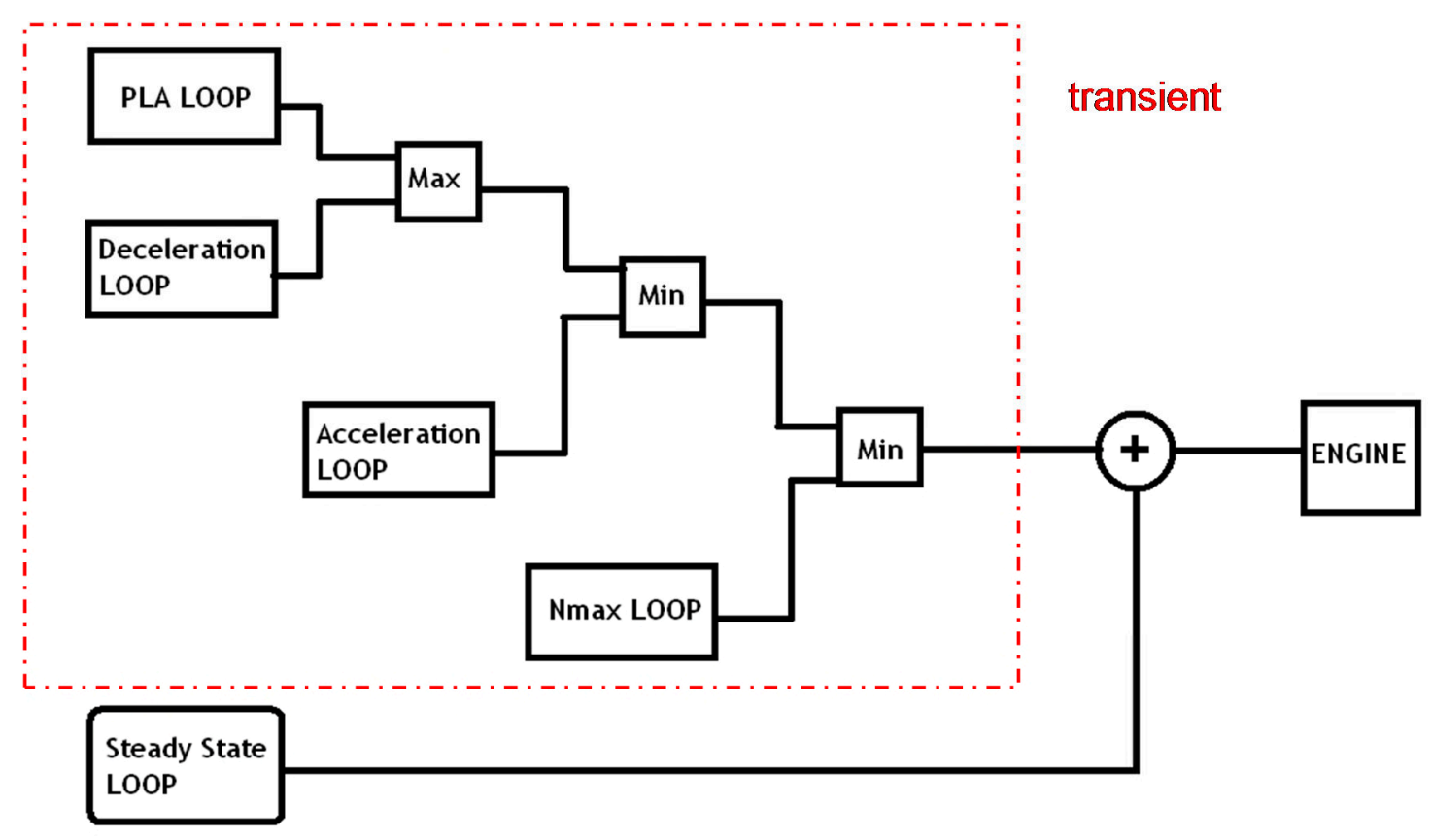

Figure 9. Min-Max control strategy for a single spool turbojet engine

The studies on the design and control structure development for gas turbines are still ongoing in academia and industry. Finding the optimum control structure is a challenging, high level, demanding issue with many parameters to set. This field has a high potential for MGO algorithms application because of its nonlinear and switching 
nature and having the mixture of discrete and continuous parameters. However, there are not a significant number of studies addressing the MGO application in gas turbines CSD. This is attributed to the complicated nature of the objective function formulation in the optimization tool. In one of these studies, Thompson et al. discussed the implementation benefits and penalties of multi-objective optimisation approach application to a military gas turbine engine control system architecture design [52]. They applied multidisciplinary multi-objective optimization to the design of a distributed gas turbine engine controller architecture for an Advanced Short Take Off/Vertical Landing (ASTOVL) aircraft by introducing the idea of relative ranking of architectures into "good" or "bad" categories. They also concluded that this could be considered as fundamental to architecture evaluation and can also be used to highlight good design characteristics which are to be encouraged and also bad design characteristics which are to be discouraged. Moreover, they proposed for the next steps:

- To address addition of further objectives within the optimisation process;

- To do sensitivity analysis;

- To enhance visualisation techniques to extract good and bad design practices. In addition, Fleming and Purshouse reviewed the EAs applications in control systems in 2002 [53] and concluded that:

- The continued progress in computer technology will permit further realisation of the EA methodology's potential.

- The combination of an EA search and optimisation method with complementary techniques to create hybrid algorithms is seen as vital in order to create a fully effective tool.

A comprehensive discussion on the obstacles of using MGO in real-world engineering problems from engineering optimization point of view is addressed in [54]. 
Other implementation issues like:

- The capability of the optimization tool in dealing with both discrete and continuous spaces simultaneously

- The convergence guarantee in the presence of different spaces

- The smart definition of the objective function to cover all criteria are discussed recently by Famularo et al. [55].

However, taking the current ongoing projects dealing with development of GO approaches for mixed-Integer problems (Imperial College [56], ETH [57], etc. [58, 59]) into account, it is envisaged that application of these methods in gas turbine CSD would be a wide field of study in the near future.

\subsection{Meta-heuristic global optimization algorithms in control gain tuning of gas turbine engines}

The most challenging issue in controller design for a GTE, is to tune the gains of control loops simultaneously in order to get an optimal performance for the designed controller and the GTE as well. The GTE models as well as their control strategies are nonlinear, switching systems with huge number of parameters. Consequently, tuning the parameters is not affordable using analytical methods because of the computational load and trapping in local optimum issues. Therefore, the application of non-analytical optimization algorithms in a GTE gain tuning procedure is an attractive topic for the researchers in the field.

The first applications were reported by Fleming and his research group in the University of Sheffield in 1996 [60] in which a multi-objective genetic algorithm was used to extract a Pareto front set of solution for multivariable control of a gas turbine engine. Later on, they published two other research studies on tuning of decentralised 
PI/PID controllers for gas turbine engine control purposes [61-62] where they showed the ability and effectiveness of the global optimization approaches in industrial control applications.

During the last two decades several interesting studies on application of MGO for gas turbine engine controller gain tuning were done by the researchers in different ways. Decoupling the control loops [63] multivariable control [64] mean square error (MSE) objective function [65] safety considerations [66], Multi Criteria Decision Making (MCDM) [67], and centralized and decentralized control loops gain tuning [68, 4] are some of the most important approaches taken by the researchers in this regard. Generally, the implemented procedure in all of them could be described as follows:

I. Creation of the engine model (as discussed in chapter 3.1). This model usually is a reduced-order model in order to be fast and also precise enough to be used in iterative optimization procedures

II. Control structure design (as discussed in chapter 3.2). This structure is designed based on the control modes that needs to be satisfied simultaneously

III. Definition of the gain tuning procedure as an engineering optimization problem. The pre-defined objective function can focus on different aspects (e.g. response time, fuel consumption, manoeuvrability, safety consideration, etc.)

a. The objective function could be a combination of different criteria as well. It could be defined in the form of single objective with weighted indices or in the form of a vector with different elements for multi-objective optimization purpose. Table 2 shows a sample of a single-objective (2) and a multi-objective (3) function for a turbojet engine controller gain tuning problem 
IV. Adding other constraints and limitations as penalty functions ( $P_{i}$ in equations 1 and 2) or new indices to the objective function

V. Choosing the optimization algorithm to deal with the defined problem and setting the algorithm parameters

VI. Running optimization and getting the results (set or sets of optimized gains)

The flowchart of global optimization application in gas turbine engine controller gains tuning is shown in figure 10. This research area is still interesting and many researchers are discussing different aspects of this topic.

Table 2 - Objective function samples for controller gain tuning

\begin{tabular}{|c|c|c|c|}
\hline [67-68] & \multicolumn{3}{|c|}{ Objective Functions } \\
\hline $\begin{array}{l}\text { Single- } \\
\text { Objective }\end{array}$ & $J($ controller gains $)=\frac{1}{\beta_{1}+\beta_{2}}$ & $\left(\beta_{1}\left\{\frac{t_{\text {acc }}+t_{\text {dec }}}{\text { sim }_{\text {time }}}\right\}+\beta_{2} \int_{0}^{s i m_{\text {time }}}\right.$ & $\left.\frac{\dot{m}_{f}}{\left\{\dot{m}_{f}\right\}_{\text {max }} \times \frac{\text { sim }}{\text { sampleTime }}} d t\right)+\sum \alpha_{i} P_{i}(2)$ \\
\hline $\begin{array}{l}\text { Multi- } \\
\text { Objective }\end{array}$ & $J($ controller gains $)=\left[\int_{0}^{s i m_{\text {time }}}\right.$ & 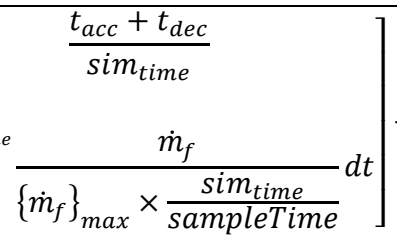 & $+\left[\begin{array}{l}\alpha_{1} P_{1} \\
\alpha_{2} P_{2}\end{array}\right]$ \\
\hline
\end{tabular}

The above table shows a sample of a single-objective and a multi-objective function used for turbojet engine controller tuning problem in [59] and [60]. Where:

- $\dot{m}_{f}$ The instantaneous total fuel flow to the combustion chamber;

- $\left\{\dot{m}_{f}\right\}_{\max }$ Maximum allowable fuel flow in any time step;

- $\quad$ sim_time Simulation time;

- sampleTime Time step;

- $t$ Time index; 
- $t_{a c c}, t_{d e c}$ Acceleration and deceleration times;

- $\beta_{i}$ Weighting coefficients (set by the designer respect to the importance of objective function indices. It is obvious that $\sum \beta_{i}=1$ );

- $\alpha_{i}$ Weighting coefficients for penalty functions (set by the designer respect to the importance of penalty functions. It is obvious that $\sum \alpha_{i}=$ 1);

- $\quad P_{i}$ Penalty functions (e.g. over speed, over temperature, etc.);

The objective function includes two performance indices. The performance indices are normalized first and then weighted according to their importance by coefficients $\beta_{i}$. In addition, $t_{a c c}, t_{d e c}$ are the acceleration and deceleration times, which the engine requires to follow the PLA command (settling times with e.g. $\pm 2 \%$ error). Therefore, these functions consider the engine response time and fuel consumption simultaneously.

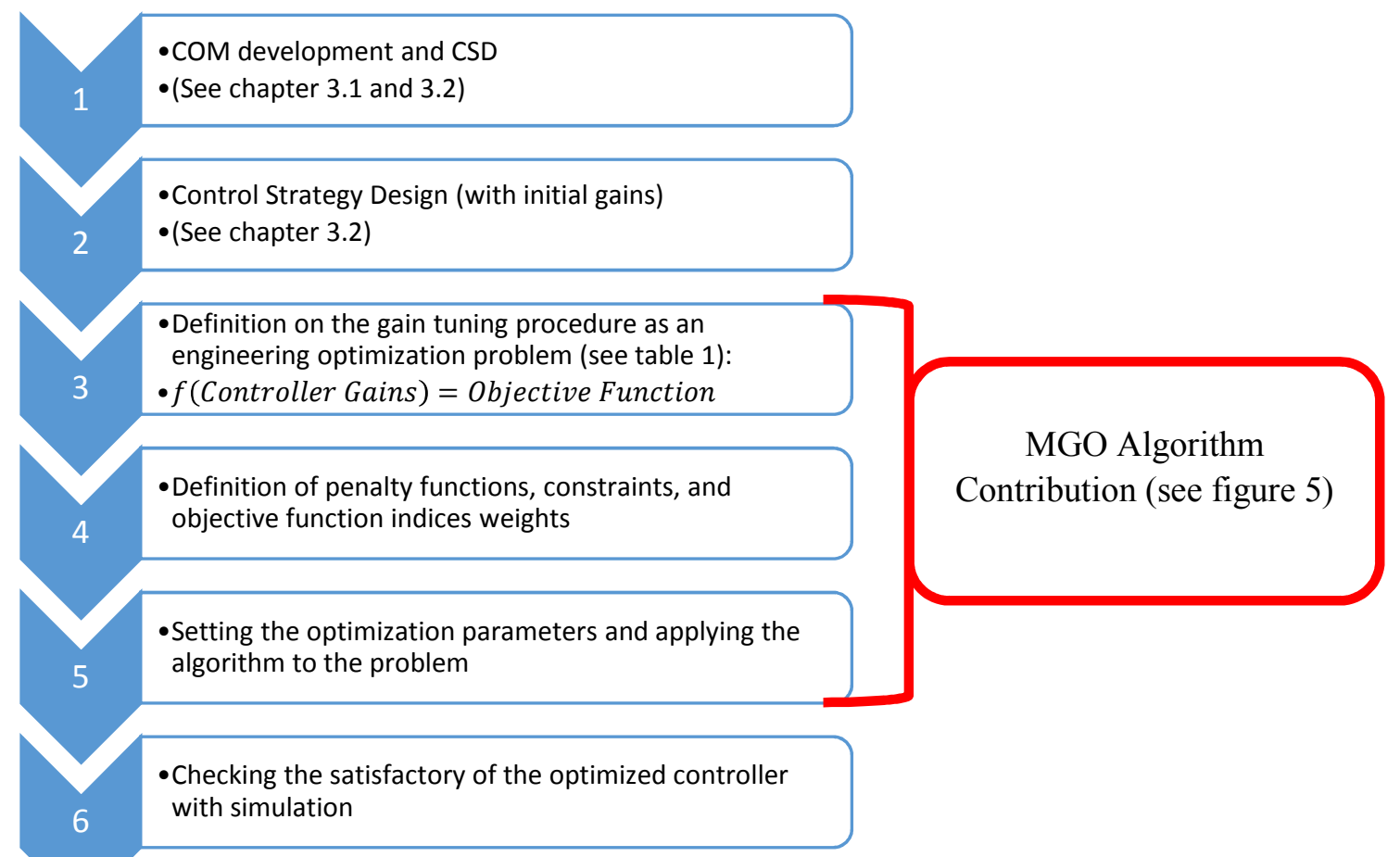


Figure 10 - application of global optimization algorithms in gas turbine engines controller gain tuning

\section{The research challenges for application of meta-heuristic global optimization} algorithms in gas turbine engine modelling and control

In addressing high-level research requirements for the MGO application in GTEs, one should return to the question as to what are the new aircraft engine modelling and controller design challenges and how MGO approaches could deal with them.

- It is evident that one of the biggest challenges is to cope with interminable increasing number of parameters in new designs of aircraft engines (e.g. UltraHigh Bypass Ratio (UHBR), open rotors, Hybrid propulsion, etc.). The new designs of aircraft engines are increasingly complex and many parameters should be designed and tuned simultaneously for the optimal performance of the engine and the aircraft. Moreover, the new advances in control algorithms and gas turbine engine and accessories manufacturing process make matters worse since the optimization running time increases with increasing the number of the parameters noticeably.

- A second major issue is the reliability and repeatability of the MGO methods. A proof of convergence to the global optima (not trapping in local ones) is still an unsolved issue in MGO techniques. This does not make for an easy transition to a practical MGO based approach from existing largely conventional control systems implemented on ECUs. This is actually indicative of the non-analytic optimization algorithm being uncertain.

In general, a good compromised MGO based approach is needed to refine any design before committing it to hardware. This is to ensure that the benefits of a system generate sufficient advantageous margin, particularly in terms of improvements in 
performance and safety. The recent and current efforts to cope with the abovementioned challenges and to smooth the implementation direction of MGO algorithms in gas turbine engine applications could be categorized in two main fields:

\subsection{New or modified optimization algorithms based on advanced computational concepts}

Among the numerous optimization techniques proposed for different applications, only some of them are capable enough to offer reliable results in the flow of continuously new techniques. The most famous ones are Genetic Algorithm (GA), Particle Swarm Optimization (PSO), Ant Colony Optimization (ACO), and Bee Colony Optimization (BCO). All of them are nature-inspired algorithms and are very successful in different applications. However, by increasing the number of parameters, the efficiency (static and dynamic convergence) and computational affordability of MGOs will drop noticeably [69-70]. Therefore, computer scientists are working on the principles of these methods in order to enhance the convergence rate, run time etc.

Application of the linkage learning methods in EAs is one of these newly established modifications in which the linkage concept is used to apply to the evolutionary optimization algorithms operators to work on an optimal Building Blocks (BBs). The basic idea was proposed by Harik on Genetic Algorithm as a combination of the coding scheme and an exchange crossover operator to create an evolvable genotypic structure [73]. This method (and methods like this) is currently under consideration by computer researchers [71-72]. It has a great potential for application in huge size realworld engineering problems and especially in advanced gas turbine engine problems. 
The linkage learning techniques use the ability to learn functional dependency between genes to deduces the probability that sets of functional dependent values are split up when crossover is performed [74].

In order to confirm the ability of the linkage learning method in enhancement of the global optimization behaviour, an illustrative case study simulation is presented in this section and the results are compared with those of the previous published studies.

For this purpose, the controller gains of a turbojet engine modelled in figures 3 and 4 will be tuned using Competent Genetic Algorithm (CGA), which is a version of genetic algorithm combined with a linkage-learning algorithm to find the linkage groups and organize the building blocks in the optimization approach.

The engine schematic and characteristics are presented in figure 3. A simple Min-Max control algorithm is designed for the engine based on steady-state control mode, transient control mode, and physical limitation control modes as shown in figure 11. The modelling and control procedure is confirmed and validated in $[3,4,35$, and 68]. The optimization algorithm is to tune the four control loop gains in order to minimize the objective function of equation 2 defined in Table 1.

This controller is tuned with genetic algorithm in [3], with particle swarm optimization in [35], and with Invasive weed optimization in [68]. Now, the CGA is applied to the model and the results are compared with other methods from different points of view. To make the comparison fair, the objective functions, initial population, population size, number of iterations, stopping criteria and other boundary and initial conditions are set the same for all algorithms. In addition, the presented results are the average of 15 runs to deal with repeatability issues of MGO algorithms. 


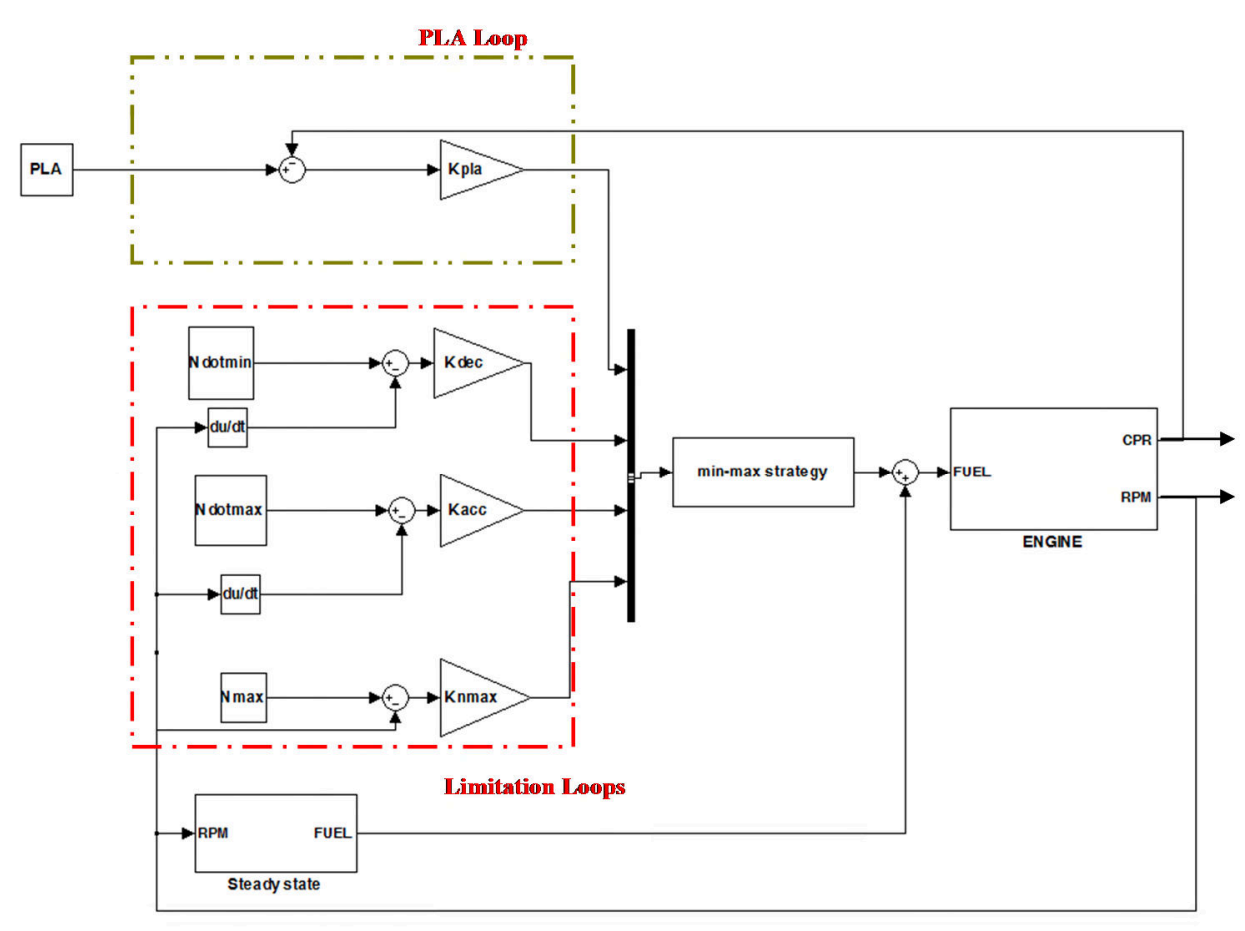

Figure 11 - The Min-Max control strategy for the turbojet engine

The working mechanism of the CGA is to enhance the GA performance by the processing of the Building Blocks (BBs) of the problem that are groups of interacting solution elements, each of which constitute a partial solution to the problem [75]. A group of highly linked locus or variables that forms a BB is called a linkage group. To solve the linkage-learning problem, linkage groups must be detected. Linkage groups form an interaction model of the problem that describes the interactions between variables of the problem. Once linkage groups are detected accurately, the optimization algorithm can perform the mixing task efficiently and accurately without BB disruption leading to appropriate convergence [76]. This procedure avoids doing unnecessary cross over between the parameters which do not belong to a different linkage group.

Figures 12 and 13 show the results of static and dynamic convergence of the used algorithms respectively. As shown in figure 12, the CGA overcomes the GA and IWO from the static convergence point of view (reached to the final solution in less 
generations). Although PSO has almost the same static convergence rate as the CGA, the CGA merits are the higher reliability and repeatability in comparison with PSO because of working with BBs and Dependency Structure Matrix (DSM). Figure 13 also shows that the CGA is better than GA and PSO in dynamic convergence index and performs almost the same with IWO in this index.

The most important point about the CGA is shown in table 3, which compares the computational efforts of all algorithms. It can be seen that the CGA exceeds the IWO, GA, and PSO from the required computational effort point of view. Therefore, CGA has the potential to deal with the new advanced engine designs as it will be able to tune many more parameters with affordable computational run time. In other words, adding the linkage learning ability to the GA (and other EAs) enables it to afford more complex and huge size problems and to cope with the first challenge mentioned earlier (the computational capability in huge problems).

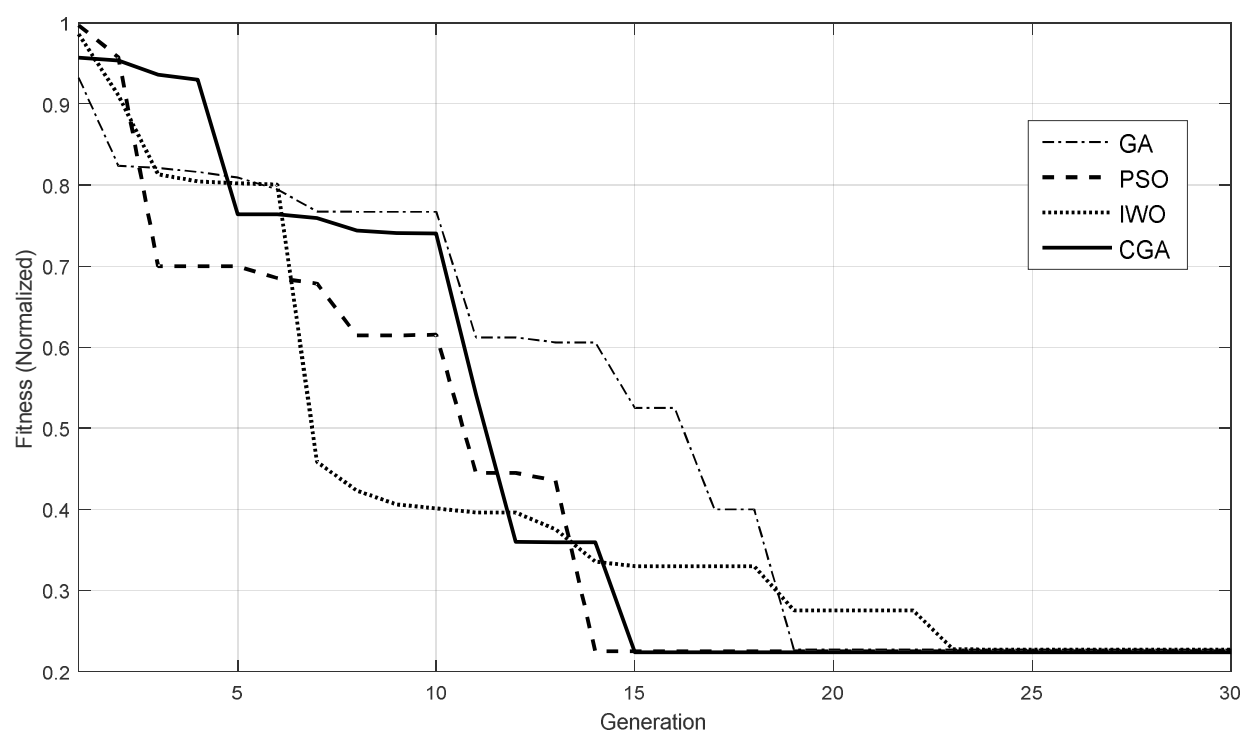

Figure 12 - Static convergence comparison of optimization algorithms for Min-Max controller gain tuning of the turbojet engine (average of 15 runs) 


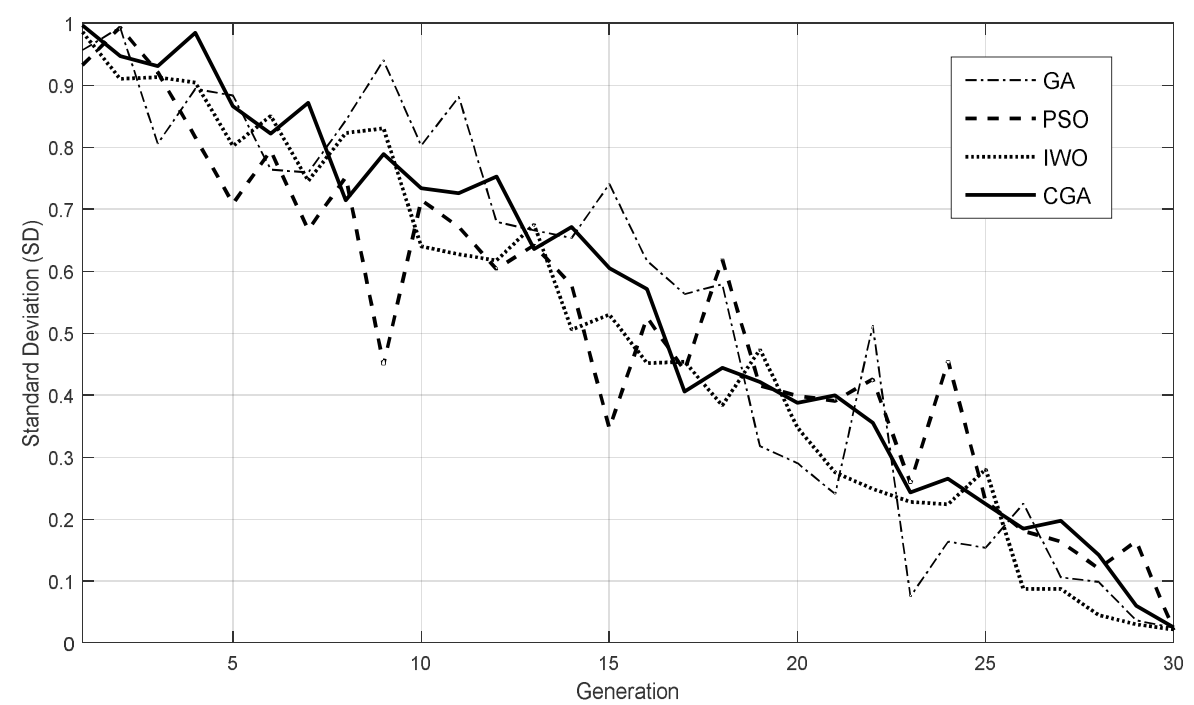

Figure 13 - Dynamic convergence comparison of optimization algorithms for MinMax controller gain tuning of the turbojet engine (average of 15 runs)

Table 3 - Computational effort comparison of optimization algorithms for Min-Max controller gain tuning of the turbojet engine (average of 15 runs)

\begin{tabular}{|l|l|l|l|l|}
\hline & GA & PSO & IWO & CGA \\
\hline Simulation time (min : sec) & $23: 34$ & $16: 12$ & $33: 15$ & $13: 10$ \\
\hline
\end{tabular}

\subsection{Combination of gradient-based and non-gradient based methods}

The other approach for dealing with the research challenges of MGO techniques in GTE applications is to work on developing new types of algorithms by combination of MGO approaches and gradient-based methods [77] usually called "Hybrid Algorithm" as discussed in [53-54]. A hybrid algorithm is an algorithm that combines two or more other algorithms that solve the same problem, either choosing one (depending on the data), or switching between them over the course of the algorithm. This is generally 
done to combine desired features of each, so that the overall algorithm is better than the individual components [78-79].

By using one of these recent methods, a multi-objective optimization problem can be converted to a single objective optimization problem to decrease the running time while keeping the advantages of Pareto front results. The aggregative gradient-based method proposed by Izui et al. in 2014 [80] is a combination of genetic algorithm and an aggregative gradient-based method dealing with a weighting method to obtain Pareto-optimal solutions. This algorithm determines the adaptive weighting coefficients for each point with solving a linear programming problem [80-81]. After linear approximation of the converted single objective problem, the design variables are updated by a linear programming technique. Moreover, since a part of this algorithm is analytic, the reliability and repeatability of the algorithm will be enhanced noticeably; and it would address the second mentioned challenge (reliability and repeatability) as well.

To investigate the ability of the hybrid methods to deal with new challenges of the gas turbine engine modelling and control designs, the turbojet engine controller discussed in the previous section is tuned using aggregative gradient-based method in a multiobjective feature using the objective function of the equation 3 In table 2. The controller with this vector objective function is tuned by Multi-objective particle swarm optimization (MOPSO) in [35], by Multi-objective invasive weed optimization (MOIWO) in [67] and with Multi-objective genetic algorithm (MOGA) in [3]. The results of applying aggregative gradient-based method to the problem is presented in figure 14 and table 3. Again, the advantage of saving computational effort is clear from table 4. Moreover, the other relative merits of hybrid optimization algorithms is their reliability and 
repeatability since they use analytical steps as well. It enables them to deal with both challenges introduced earlier.

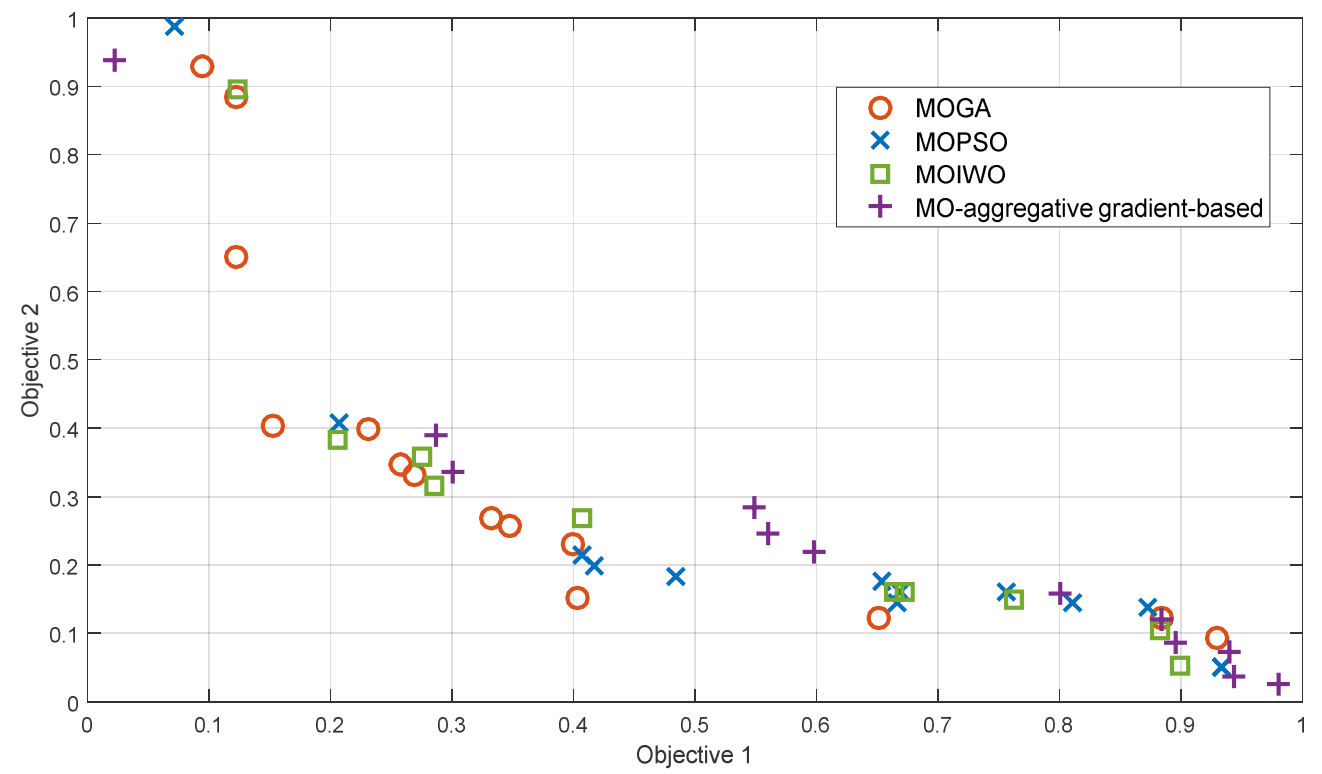

Figure 14 - Pareto front comparison of optimization algorithms for multi-objective Min-Max controller gain tuning of the turbojet engine

Table 4 - Computational effort comparison of optimization algorithms for multiobjective Min-Max controller gain tuning of the turbojet engine (average of 15 runs)

\begin{tabular}{|l|l|l|l|l|}
\hline & MOGA & MOPSO & MOIWO & MO- aggregative gradient-based \\
\hline Simulation time (min : sec) & $32: 14$ & $24: 20$ & $48: 14$ & $16: 10$ \\
\hline
\end{tabular}

\section{Exploring the future of meta-heuristic global optimization algorithms in gas}

\section{turbine engine applications}

In order to explore the future of the MGO methods in GTE applications it is worthy to summarize the current ongoing progresses in the GTE field. Main progresses in modelling and control of gas turbine engines could be explained as follows:

- New GTE models [82]: the new, advanced models for gas turbines include more complicated details and parameters than previous ones. The more complicated 
the model the more parameters to deal with by designers. As mentioned before, the performance of the global optimization algorithms drops noticeably with increasing the number of the parameters. So, the optimization algorithms should be enhanced in parallel with these advancements in modelling approaches. For instance, Mitsubishi reported that the combustion temperature of power generation plants is increasing at a rate of approximately $20 \mathrm{degC}$ per year. There are some technical issues in this regard like reducing NOx emissions and the need for higher strength materials. This matter causes compromising effects on the objective function definition of the engineering problems [83-85].

- New research topics in control [86-88]: CSD, and controller gain tuning with new research topics are entering in a new era in which advanced concepts like consensusability [89], formationability [90] and computability [91] have emerged beyond the scope of the traditional plant, sensor, and actuator structure. Therefore, new objectives and concerns in the future controllers should be considered which are clearly more sophisticated and demanding than the current ones.

It could be summarized that the enhanced optimization algorithms using advanced computational methods and the hybrid optimization algorithms using gradient based feature could deal with the new challenges in aircraft engine design, modelling and controller optimization. Table 5 summarizes these challenges and potential solution.

Table 5 - Future challenges of MGO applications in GTE modelling and control problems with proposed solutions 


\begin{tabular}{|c|c|c|c|c|}
\hline & Challenge & Caused by & Potential solution & Evidence \\
\hline 1 & $\begin{array}{l}\text { Unaffordable computational } \\
\text { time respect to the huge } \\
\text { number of parameters to deal } \\
\text { with }\end{array}$ & $\begin{array}{l}\text { Complex designs } \\
\text { of new gas } \\
\text { turbine engines } \\
\text { (e.g. NEA, MEA, } \\
\text { UHBR engines, } \\
\text { etc.) }\end{array}$ & $\begin{array}{c}\text { Enhanced } \\
\text { optimization } \\
\text { algorithms (e.g. } \\
\text { Stud GA, } \\
\text { Competence GA, } \\
\text { Linkage learning, } \\
\text { etc.) }\end{array}$ & $\begin{array}{c}\text { [38], [71-73], } \\
\text { Figure 12, } 13, \\
\text { Table } 3\end{array}$ \\
\hline 2 & $\begin{array}{l}\text { Finding global optimum for } \\
\text { new challenging objective } \\
\text { functions (repeatability and } \\
\text { reliability) }\end{array}$ & $\begin{array}{l}\text { New systems and } \\
\text { components in } \\
\text { modern aircraft } \\
\text { engines }\end{array}$ & $\begin{array}{c}\text { Hybrid } \\
\text { optimization } \\
\text { algorithms }\end{array}$ & $\begin{array}{c}\text { [77-81], Figure } \\
\text { 14, Table } 4\end{array}$ \\
\hline
\end{tabular}

\section{CONCLUSIONS}

MGO algorithms for GTE modelling and controller design and tuning procedures over the past two decades were examined. Initially, the mathematical principles and benefits of GO algorithms were expounded with the classification of these algorithms into three main categories where their pros and cons were explained. Several proposed applications of MGO in GTE problems dating back to 1996 were examined. Three application classes were defined to help to put historical concepts into context. A systematic examination of the critical areas in GTE modelling, control structure design, and controller tuning successfully identified the remaining research challenges for MGO algorithms in new advanced GTEs applications. These remaining research challenges include the following:

- To reduce the considerable computational efforts caused by many more parameters in the new GTE designs and controllers; 
- To gain a better reliability and repeatability of the MGOs in the presence of many parameters of the new engine designs.

If these research challenges are overcome, it will then be possible to establish a generic framework for MGO applications in GTE design and control problems. The potential solutions for the identified challenges are proposed:

- To use advanced computational methods (e.g. linkage learning techniques) to enhance the efficiency of the MGOs and to increase their affordability for dealing with huge problems;

- To use hybrid optimization algorithms using both meta-heuristic and gradientbased algorithms to enhance the reliability of the algorithms to cope with more complex objective functions.

The effectiveness of both solutions are confirmed by simulation results and analysis. Finally, it will allow the GTE modelling and control problems to be understood in order to adopt a robust and enhanced MGOs that gives assurances of optimal results for all new advancements of GTEs.

\section{References}

[1] S. D. Hancock, Gas Turbine Engine Controller Design Using Multi-Objective Optimization Algorithms, PhD Thesis, University of Wales, Bangor, (1992)

[2] M. Fonseca, Carlos \& Fleming, Peter. Genetic Algorithms for Multi-objective Optimization: Formulation Discussion and Generalization. The fifth Intl conference on Genetic Algorithms. (1993).

[3] S. Jafari, M. Montazeri-Gh. Evolutionary Optimization for Gain Tuning of Jet Engine Min-Max Fuel Controller. Journal of Propulsion and Power. 27. (2011). 1015-1023. 10.2514/1.B34185.

[4] M. Montazeri-Gh, S. Jafari, and M. Nasiri. "Application of particle swarm optimization in gain tuning of integrated flight and propulsion control." International Journal of Aerospace Sciences 2.3 (2013): 5570.

[5] A.Neumaier, Complete Search in Continuous Global Optimization and Constraint Satisfaction, pp. 271-369 in: Acta Numerica 2004 (A. Iserles, ed.), Cambridge University Press 2004.

[6] J. E. Beasley, editor. Advances in Linear and Integer Programming. Oxford Science, 1996. (Collection of surveys) 
[7] Williams, H.P.. Logic and integer programming. International Series in Operations Research \& Management Science. 130. (2009). ISBN 978-0-387-92280-5.

[8] Ruszczyński, Andrzej. Nonlinear Optimization. Princeton, NJ: Princeton University Press. pp. xii+454. (2006). ISBN 978-0691119151. MR 2199043

[9] Avriel, Mordecai. Nonlinear Programming: Analysis and Methods. Dover Publishing. (2003). ISBN 0-486-43227-0.

[10] J. C. Spall. Introduction to Stochastic Search and Optimization. Wiley. (2003). ISBN 0-471-330523 .

[11] M. C. Fu. "Optimization for Simulation: Theory vs. Practice". INFORMS Journal on Computing 14 (3): 192-227. (2002). doi:10.1287/ijoc.14.3.192.113.

[12] M.C. Campi and S. Garatti. The Exact Feasibility of Randomized Solutions of Uncertain Convex Programs. SIAM J. on Optimization, 19, no.3: 1211-1230, 2008.

[13] H. Robbins, S. Monro. "A Stochastic Approximation Method". Annals of Mathematical Statistics 22 (3): 400-407. (1951). doi:10.1214/aoms/1177729586.

[14] J. Kiefer; J. Wolfowitz. "Stochastic Estimation of the Maximum of a Regression Function". Annals of Mathematical Statistics 23 (3): 462-466. (1952). doi:10.1214/aoms/1177729392.

[15] J. C. Spall. "Multivariate Stochastic Approximation Using a Simultaneous Perturbation Gradient Approximation". IEEE Transactions on Automatic Control 37 (3): 332-341. (1992). doi:10.1109/9.119632.

[16] Bianchi, Leonora; Marco Dorigo; Luca Maria Gambardella; Walter J. Gutjahr. "A survey on metaheuristics for stochastic combinatorial optimization". Natural Computing: an international journal 8 (2): 239-287. (2009). doi:10.1007/s11047-008-9098-4.

[17] C. Blum, A. Roli, "Metaheuristics in combinatorial optimization: Overview and conceptual comparison" 35 (3). (2003) .ACM Computing Surveys: 268-308.

[18] D.E. Goldberg. Genetic Algorithms in Search, Optimization and Machine Learning. Kluwer Academic Publishers. (1989). ISBN 0-201-15767-5.

[19] F. Glover, G.A. Kochenberger. Handbook of metaheuristics 57. Springer, International Series in Operations Research \& Management Science. (2003). ISBN 978-1-4020-7263-5.

[20] E-G. Talbi. Metaheuristics: from design to implementation. Wiley. (2009). ISBN 0-470-27858-7.

[21] Sörensen, Kenneth. "Metaheuristics—the metaphor exposed" . International Transactions in Operational Research. (2013). doi:10.1111/itor.12001.

[22] Montazeri-Gh, M., H. Yousefpour, and S. Jafari. "Fuzzy logic computing for design of gas turbine engine fuel control system." Computer and Automation Engineering (ICCAE), 2010 the 2nd International Conference on. Vol. 5. IEEE, 2010.

[23]. H. Gold, and S. Rosenzweig, A method for estimating speed response of gas-turbine engines, in National Advisory Committee for Aeronautics. (1952), Research Memorandum E51 K2 1. Washington.

[24]. J.O.N. Lawrence, , and R.D. Powell, The application of servo-mechanism analysis to fuel control problems. Proceedings of the Institute of Mechanical Engineers. (1957).

[25]. C. Evans, Testing and modeling aircraft gas turbines: an introduction and overview, UKACC International Conference on Cntrol. (1998), Conference Publication No. 455.

[26]. C. Evans, Identification of linear and nonlinear systems using multi-sine signals, with a gas turbine application, in School of Electronics. (1998), PhD Thesis in University of Glamorgan.

[27]. J.W. Fitchie, S.W. White, R.H. Cronshaw, and H.J. Willcocks, , An experimental and theoretical study of the response of a two shaft turbojet subjected to small disturbances. (1959): National Gas Turbine Establishment (UK), Note NT 420. 
[28]. Staff . Thermodynamic model of the Spey engine. Linearized for Rolls Royce by Stirling Dynamics Ltd. (1993): DERA Pyestock.

[29]. H.I.H. Saravanamuttoo, , and M.S. Maclsaac, , An overview of engine dynamic response and mathematical modelling concepts, AGARD Conference Proceedings No. 324. (1982). Engine Handling.

[30]. D.S. Garg, Propulsion Control and Diagnostics Research under NASA Aeronautics Research Mission Programs, C.O. Workshop at Ohio Aerospace Institute, Editor. Nov. 6-7, (2007), Glenn research centre, NASA.

[31]. G.G. Kulikov, and H.A. Thompson, Dynamic Modeling of Gas Turbines. (2003): industrial control center, Glasgow, Scotland, U.K.

[32]. A. Wills,; B. Ninness, Generalised Hammerstein-Wiener system estimation and a benchmark application. Control Eng. Pract. 2012, 20, 1097-1108.

[33]. J. Paduart,; L. Lauwers,; R. Pintelon,; J. Schoukens, Identification of a Wiener- Hammerstein system using the polynomial nonlinear state space approach. Control Eng. Pract. 2012, 20, 1133-1139.

[34]. M. Lichtsinder, , Y. Levy, Jet engine model for control and real-time simulation journal of engineering for gas turbine and power, 2006. 128(ASME): p. 745-753.

[35] M. Montazeri-Gh, S. Jafari, MR. Ilkhani Application of particle swarm optimization in gas turbine engine fuel controller gain tuning. Engineering Optimization. 2012 Feb 1;44(2):225-40.

[36]. R. Andoga, , L. Fozo, , L. Madarász, , Approaches in Modeling of a Small Turbojet Engine MPM 20, in 978-1-4244-2106-0/08/ @ (2008) IEEE.

[37]. http://www.leteckemotory.cz/motory/microturbo/ , last updated on this page: 25 January 2003

[38] Rodriguez-Vazquez,V., Fonseca C M, and Flemig, P.J, 1997a, An Evolutionary Approach to Nonlinear System Identification, 11th IFAC symposium on system identification, 3, 1395-1400

[39] Rodriguez-Vazquez,V., Fonseca C M, and Flemig, P.J, 1997b, Multiobjective Genetic Programming; a Nonlinear System Identification Application, Late Breaking Papers at the Genetic Programming 97 Conference. 207-212

[40]. Rodriguez-Vazquez,V., and Flemig, P.J., Multi-objective genetic programming for gas turbine engine model, in UKACC International conference on control. (1998). IEE.

[41]. Valceres, V.R., Silva, W.k., Fleming, P.J., performance optimization of gas turbine engine. Engineering applications of artificial intelligence, vol.18: 2005.

[42]. D. Ashlock, Evolutionary Computation for Modeling and Optimization. Doi: 10.1016/j.ecompanop.2004.05.075. 2004.

[43] Stephen Ogaji, Pericles Pilidis, Richard Hales, TERA- A Tool for Aero-engine Modelling and Management, 2nd World Congress on Engineering Asset Management and 4th International Conference on Conditiion Monitoring, 11-14th June 2007, Harrogate, UK

[44] E. Tsoutsanis, Y. G. Li, P. Pilidis and M. Newby, Part-Load Performance of Gas Turbines: Part II - Multi-Point Adaptation With Compressor Map Generation and GA Optimization, ASME 2012 Gas Turbine India Conference, ASME 2012 Gas Turbine India Conference, Mumbai, Maharashtra, India, December 1, 2012, Conference Sponsors: International Gas Turbine Institute

[45] Cesar Celis, Vishal Sethi, Riti Singh, Pericles Pilidis, On Optimisation of Environmentally Friendly Aircraft Engine Cycles, J. Aerosp. Technol. Manag., São José dos Campos, Vol.7, N 2, pp.143-156, Apr.-Jun., 2015.

[46]. Austin Spang, H., Brown, H., Control of jet engines. Control Engineering Practice, vol.7 (1999): pp. 17-35.

[47]. ARP 755A, Aerospace recommended practise. 1974, Society of Automotive Engineers. 
[48]. K. Seldner, , R. James, Mihaloew, and Ronald, J. Blaha, Gneralized simulation technique for turbojet engine system analysis, Technical Note, Editor, Lewis Research Center National Aeronautics and Space Administration Cleveland, Ohio 44135.1972.

[49]. A. Kreiner, K. Lietzau, The use of onboard real-time models for jet engine control. (2002), MTU Aero Engines report, Germany. pp. 27-41.

[50]. D.S. Garg, Fundamentals of Jet Engine Control, NASA, Editor. (2008), Glenn Research Center, Controls and Dynamics Branch.

[51] Jeffrey Csank, Ryan D. May, Jonathan S. Litt and Ten-Huei Guo, Control Design for a Generic Commercial Aircraft Engine, NASA/TM-2010-216811, October 2010

[52] H.A. Thompson, A.J. Chipperfield, P.J. Fleming, C. Legge, Distributed aero-engine control systems architecture selection using multi-objective optimisation, Control Engineering Practice 7 (1999) 655-664

[53]. Fleming, P.J., Purshouse, R.C., Evolutionary algorithms in control systems engineering: a survey. Control Engineering Practice, vol.10:2002. :pp. 194-202.

[54] Venkataramanan Balakrishnan Stephen Boyd, Global Optimization in Control System Analysis and Design, Information Systems Laboratory Department of Electrical Engineering Stanford University Stanford, CA 94305 U. S. A

[55] D. Famularo, P. Pugliese, Ya D. Sergeyev, Control system design using global optimization techniques, Progress in system and robot analysis and control design Volume 243 of the series Lecture Notes in Control and Information Sciences pp 107-116, 2007

[56] Global Optimisation of Mixed-Integer Nonlinear Programs, Imperial College London, Department of Computing, Quantitative Analysis and Decision Science, ongoing project, Ruth Misener, http://wp.doc.ic.ac.uk/rmisener/project/global-optimisation-of-mixed-integer-nonlinear-programs/

[57] Mixed Integer Optimization, ETH Zurich, Institute for Operations Research, ongion project, Robert Weismantel, https://www.math.ethz.ch/ifor/research/mixed-integer-optimization.html

[58] S. Lucidi, F. Rinaldi, An Exact Penalty Global Optimization Approach for Mixed-Integer Programming Problems, Dipartimento di Informatica e Sistemistica Sapienza Universit'a di Roma, 2011

[59] Zeynep H. Gümüş, Christodoulos A. Floudas, Global optimization of mixed-integer bilevel programming problems, Computational Management Science, July 2005, Volume 2, Issue 3, pp 181212

[60] A. Chipperfield, , P.J. Fleming, Multi-objective gas turbine engine controller design using geneticalgorithm. Industrial electronics, IEEE, vol.43: (1996). pp. 55-67.

[61] S. Tavakoli, , I. Griffin, , and P.J. Fleming, , Tuning of decentralised PI (PID) controllers for TITO processes Control Engineering Practice, (2005).

[62]. S. Tavakoli, , I. Griffin, and P.J. Fleming, Decentralized PI Control of a Rolls-Royce Jet Engine, IEEE Conference on Control Applications Toronto, Canada, August 28-31, (2005).

[63] Kim Dong Hwa, "Neuro-fuzzy tuning of PID controller for control of actual gas turbine power," 2004 IEEE International Conference onComputational Intelligence for Measurement Systems and Applications, 2004. CIMSA., Boston, MA, 2004, pp. 192-197. doi: 10.1109/CIMSA.2004.1397260

[64]. S. Tavakoli, Multivariable PID Control with Application to Gas Turbine Engines, Thesis submitted for candidature for the degree of PhD, October 2005, Department of Automatic Control and Systems Engineering The University of Sheffield

[65]. R. Oonsivilai and A. Oonsivilai, Gas Turbine Optimal PID Tuning by Genetic Algorithm using MSE, World Academy of Science, Engineering and Technology International Journal of Electrical and Computer Engineering Vol:5, No:12, 2011

[66]. Montazeri-Gh M, Safari A, Jafari S. Optimization of turbojet engine fuel control system for safety consideration. In7th Conference of Iranian Aerospace Society (Aero2008), Tehran, Iran, Feb 2008 Feb (pp. 19-21). 
[67]. Jafari S, Khalaf $P$, Montazeri-Gh M. Multi-Objective Meta Heuristic Optimization Algorithm with Multi Criteria Decision Making Strategy for Aero-Engine Controller Design. International Journal of Aerospace Sciences. 2014; 3(1):6-17.

[68]. Jafari S, Montazeri-Gh M. Invasive weed optimization for turbojet engine fuel controller gain tuning. International Journal of Aerospace Sciences. 2013; 2(3):138-47.

[69] Guindon S, Lethiec F, Duroux P, Gascuel O. PHYML Online-a web server for fast maximum likelihood-based phylogenetic inference. Nucleic acids research. 2005 Jul 1;33(suppl_2):W557-9.

[70] Polak E, editor. Optimization: algorithms and consistent approximations. Springer Science \& Business Media; 2012 Dec 6.

[71] G. Harik and D. Goldberg, "Learning linkage," in Foundations of Genetic Algorithms 4, R. Belew and M. Vose, Eds. San Francisco, CA: Morgan Kaufmann, 1997, pp. 247-262. [Online]. Available: citeseer.ist.psu.edu/article/harik97learning.html

[72] Ying-ping Chen, Linkage Learning Genetic Algorithm, Extending the Scalability of Linkage Learning Genetic Algorithms, Volume 190 of the series Studies in Fuzziness and Soft Computing pp 35-43, 2005

[73] Ying-ping Chen, Extending the scalability of linkage learning genetic algorithm: theory and practice. Dissertation Submitted in partial fulfillment of the requirements for the degree of Doctor of Philosophy in Computer Science in the Graduate College of the University of Illinois at Urbana-Champaign, 2004

[74]. J. W. Kimball, "Genetic linkage and genetic maps," December 2004. [Online]. Available: http://users.rcn.com/jkimball.ma.ultranet/BiologyPages/L/Linkage.html \#An example of linkage

[75] Tsuji, M. and M. Munetomo, Linkage analysis in genetic algorithms. Computational Intelligence Paradigms, 2008: p. 251-279.

[76]. Nikanjam, A., et al., Enhancing the Efficiency of Genetic Algorithm by Identifying Linkage Groups Using DSM Clustering, in 2010 IEEE Congress on Evolutionary Computation (CEC2010). 2010: Bacelona, Spain. p. 1-8.

[77]. Cagnina LC, Esquivel SC, Coello CAC (2011) Solving constrained optimization problems with a hybrid particle swarm optimization algorithm. Eng Optim 43(8):843-866

[78]. Kotinis M (2011) Implementing co-evolution and parallelization in a multi-objective particle swarm optimizer. Eng Optim 43(6):635-656

[79]. Mahmoodabadi M, Bagheri A, Nariman-zadeh N, Jamali A (2012) A new optimization algorithm based on a combination of particle swarm optimization, convergence and divergence operators for single-objective and multiobjective problems. Eng Optim 44(10):1167-1186

[80]. Kazuhiro Izui, Takayuki Yamada, Shinji Nishiwaki, Kazuto Tanaka, Multiobjective optimization using an aggregative gradient-based method, Struct Multidisc Optim DOI 10.1007/s00158-014-1125-8

[81]. Qu BY, Suganthan PN (2011) Constrained multi-objective optimization algorithm with an ensemble of constraint handling methods. Eng Optim 43(4):403-416

[82]. https://www.nasa.gov/feature/nasa-runs-first-ever-test-of-new-jet-engine-tech, Last Updated: Aug. 7, 2017, Editor: Kelly Heidman

[83] YASUSHI FUKUIZUMI, SHIGEHIRO SHIOZAKI, AKIMASA MUYAMA, SUMIU UCHIDA, Large Frame Gas Turbines, The Leading Technology of Power Generation Industries, Mitsubishi Heavy Industries, Ltd. Technical Review Vol. 41 No. 5 (Oct. 2004)

[84] Fukue, I., Gas Turbine Technology Past 20 Years and Next 20 Years, ASME Turbo Expo 2004

[85] Fukuizumi, Y., Future Prospect of Large Capacity Gas Turbine, CIMAC KYOTO 2004.6

[86] Rolls-Royce to acquire Aero Engine Controls, White paper, Friday, 8 June (2012), https://www.rollsroyce.com/media/press-releases/yr-2012/120608-engine-controls.aspx 
[87]. Behbahani, Alireza, Culley, Dennis, E., et al., "Status, Vision, and Challenges of an Intelligent Distributed Engine Control Architecture", SAE Paper 2007-01-3859, SAE Aerotech Congress, Los Angeles, California, September 18-20, 2007

[88]. S. Ma, J. Tan, Y. Ning and Z. Gao, "Modeling and simulation of gas turbine starter and fuel control system," 2017 36th Chinese Control Conference (CCC), Dalian, 2017, pp. 2149-2154.

doi: 10.23919/ChiCC.2017.8027674

[89]. Hengster-Movric K., Lewis F. Cooperative observers and regulators for discrete-time multiagent systems International Journal of Robust and Nonlinear Control, Volume 23, 2013

[90]. T. C. Yang, A. C. Zolotas, T. J. Wren and H. N. Yu, "Exploring future directions of control," 2014 UKACC International Conference on Control (CONTROL), Loughborough, 2014, pp. 525-530.

doi: 10.1109/CONTROL.2014.6915195

[91]. P. Collins, "A computable type theory for control systems," Proceedings of the 48h IEEE Conference on Decision and Control (CDC) held jointly with 2009 28th Chinese Control Conference, Shanghai, 2009, pp. 5538-5543. doi: 10.1109/CDC.2009.5400683 
2018-12-04

Meta-heuristic global optimization

algorithms for aircraft engines modelling

and controller design; A review,

research challenges, and exploring the future

Jafari, Soheil

Elsevier

Jafari S, Nikolaidis T. (2018) Meta-heuristic global optimization algorithms for aircraft engines modelling and controller design; A review, research challenges, and exploring the future.

Progress in Aerospace Sciences, Volume 104, January 2019, pp. 40-53

https://doi.org/10.1016/j.paerosci.2018.11.003

Downloaded from Cranfield Library Services E-Repository 